\title{
Prenatal Care Program: an Important Intervention that Needs to be Evaluated
}

\author{
Anastasia Tzelali, Stamatios Petousis*, Chrysoula Margioula-Siarkou, Panagiotis Christidis, Apostolos \\ Athanasiadis and George Mavromatidis \\ Department of Obstetrics and Gynecology, Aristotle University of Thessaloniki, Greece
}

Submission:March 19, 2018; Published: April 12, 2018

*Corresponding author: Stamatios Petousis, Department of Obstetrics and Gynecology, Aristotle University of Thessaloniki, Greece, Tel: +306934050763; Email: petousisstamatios@gmail.com

Keywords: Women; Parenting; Pregnancy; Neonatal care; Prenatal counseling program; Female reproductive system; Male reproductive system; Umbilical cord blood; Normal delivery; Vaginal delivery; Cesarean section; Epidural analgesia; Breastfeeding; Umbilical blood donation; Low socioeconomic layers

Abbreviations: PCP: Prenatal Counseling Program; AUDIT: Unpublished Internal Data

\section{Short Communication}

The preparation of both women and men for parenting, known as prenatal care, has an important role in information and treatment about pregnancy, labor, postpartum and neonatal care. Currently, despite the technological advancements, the wide use of the Internet, the constant flow of information and the high level of education in women, a lack of knowledge has been observed of future parents about prenatal care. Hence, there is a need to educate and inform prospective parents about prenatal care. Therefore, a need of creating a program of prenatal care classes has been observed, consisting of specialized professionals, to inform prospective parents, in accordance with the corresponding international standards. There are Prenatal care Programs throughout the world. The program in Ippokrateio Hospital is one of the largest in Greece and based on evidence based knowledge. The Prenatal Counseling Program (PCP) for future parents was established in 2006 at Ippokrateion General Hospital of Thessaloniki and it was created by midwives from different departments of the Hospital.

During the ten years of operation of the PCP, more than 4000 future mothers either alone or with their partners have attended the program. The women participate in the program, enter in groups according of the age of pregnancy and are advised to attend the classes usually after the 25 th week of pregnancy. The program lasts about two months. The PCP includes eight lessons with subjects varying from anatomy and physiology of the female and male reproductive system, information about umbilical cord blood donation dietation and way-of-living during pregnancy, pelvic exercises, relaxation and phsychoprophylactic methods for the labor. In particular, reference is made to the starting point of childbirth and in the development of childbirth, normal delivery, vaginal delivery and cesarean section. The women are informed about the changes in their body during pregnancy, for the management of pain during childbirth, ways to relieve pain during childbirth and epidural analgesia [1-3]. The future mothers are informed about changes in their body during postpartum and neonatal care [4]. The last 2 lessons are about breastfeeding, the benefits for both mother and baby, how to start breastfeeding after birth and how to hold their baby properly during breastfeeding [4-6]. Moreover, they are informed about potential difficulties and how to extract their breast milk and store it in the refrigerator or the freezer so they have their own milk for their baby when they return to their job. At the end of the lessons they watch a video of WHO titled "Breast is best".

The previously unpublished internal data (audit) of the prenatal care program demonstrates the beneficial effect of the PCP on the establishment of breastfeeding. According to these unpublished data, the percentage of breastfeeding babies during the first six months of life to women who attended the program of prenatal care in Ippokrateion General Hospital is up to $87.9 \%$. In contrary, according to a research of the Institution of Health for Children, in 2008 the percentage of breastfeeding babies during the first six months of life is up to $0.89 \%$. Alongside the continuous feedback from the couples who attended the PCP, evidence (of the internal data) indicate that one of the beneficial effects is stress reduction for the upcoming labor as well as first period of motherhood. Unpublished data also show increased 


\section{Global Journal of Reproductive Medicine}

vaginal delivery and a large increase in cord blood donating women in Papanikolaou Hospital of Thessaloniki. However, the first results are still unpublished and they are not result of an official research program. The data analysis of such research will give evidence of the beneficial effect of the PCP. Additionally, the effect of the PCP has not been studied at the level of specific stress-related hormones. Moreover, neither the impact of the program, nor its effect on specific sensitive population subgroups, such as single parent families, migrants parents of low socioeconomic layers and women who deliver their first child, has been studied.

Therefore, a current research has been established whose result will be soon published. The main purpose of the present effort is to study the effect of the Prenatal Program in the breastfeeding facility for at least the first six months of the newborn's life, the total time that women breastfeed, the way of

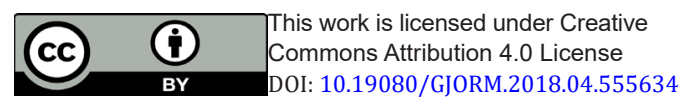

the childbirth, vaginal delivery or cesarean section, the umbilical blood donation and how helped the PCP to reduce anxiety during childbirth, postpartum and breastfeeding.

\section{References}

1. Bing E, Karmel M, Tanz A (1961) A practical training course for the psychoprophylactic method of childbirth. New York: American Society of Psychoprophylaxis in Obstetrics.

2. Barbara AH (2009) From Psychoprophylactic to Orgasmic Birth. J Perinat Educ 18(4): 45-48.

3. (2012) Breastfeeding and the use of human milk. Pediatrics 129(3): e827-e841.

4. Akkerman D, Cleland L, Croft G, Eskuchen K, Heim C, et al. (2012) Institute for Clinical Systems Improvement. Routine Prenatal Care.

5. UNISEF (2012) Preventing disease and saving resources: the potential contribution of increasing breastfeeding rates in the UK.

6. Weimer J (2001) The economic benefits of breastfeeding: a review and analysis. Food Assistance and Nutrition, Washington, DC, USA

Your next submission with Juniper Publishers
will reach you the below assets
- Quality Editorial service
- Swift Peer Review
- Reprints availability
- E-prints Service
- Manuscript Podcast for convenient understanding
- Global attainment for your research
- Manuscript accessibility in different formats
( Pdf, E-pub, Full Text, Audio)
- Unceasing customer service
Track the below URL for one-step submission
https://juniperpublishers.com/online-submission.php

